\title{
Treatment outcome of tuberculosis and associated factors at gimbi town health facilities western oromia, Ethiopia
}

\begin{abstract}
Introduction: Tuberculosis (TB) is a serious public health problem in the developing countries. Early diagnosis, effective treatment and continues assessment of treatment outcome are important indicators of TB control. Thus, the main objective of this study was to assess the treatment outcome of tuberculosis and associated factors at Gimbi town Health Facilities from July 1st 2011 to June 30 2014, West Wollega, Ethiopia.

Method: A facility based descriptive cross-sectional study on treatment outcome of all forms of tuberculosis was conducted from March 10th to 25th, 2014.Data extraction sheet which was adopted from standard unit TB registration was used to collect basic information on the profile and treatment outcome of tuberculosis patients. Finally, the collected data were entered to master sheet and then analyzed. The result of the study was presented using table, figure and with narrative descriptions. Epi info version 3.5.4 was used to analyze the data. The association between variables was calculated using Chi-square test and $\mathrm{p}$-value of $<0.05$ was considered as significant.
\end{abstract}

Result and discussion: This study revealed that a total of 120 (74\%) patients have satisfactory treatment outcome and the rest $42(26 \%)$ were with bad outcome (defaulter, Died, treatment failure and transfer out). About 33 smear positive pulmonary tuberculosis patients were registered. The cure rate and treatment success rate was $66.7 \%$ and $69.7 \%$ respectively treatment success. Co morbidity with HIV infection, treatment regimen and place of residence have significant impact on TB treatment out come with p-value $(\mathrm{P}<0.05)$.

Conclusion and recommendation: In this study, the cure rate and treatment success rate for new and retreatment PTB cases were low when compared to WHO and national target to be achieved by newly recommended DOTs strategy for TB treatment. Special attention should be given HIV positive TB patients and patients from rural residency increase the cure rate and treatment success rate
Volume 2 Issue 2 - 2017

\author{
Desalegn Garedew,' Gugsa Nemera² \\ 'Department of Gihmib zonal Health, Ethiopia \\ ${ }^{2}$ Department of Nursing, Jimma University, Ethiopia
}

Correspondence: Gugsa Nemera, Department of Nursing, Jimma University, Ethiopia, Email gugsanemera@gmail.com

Received: December 06, 2016 | Published: January 26, 2017

\section{Introduction}

Tuberculosis, a disease caused by Mycobacterium tuberculosis (tubercle bacilli) is infectious disease spread from active cases to susceptible host through air when infectious person coughs or sneezes. ${ }^{1-3}$ While Tuberculosis can affect many areas of the body, by far the most common site is the lung that accounts for $85 \%$ of TB cases. If untreated, TB leads to deaths within 5 years in at least half of the patients. Without treatment, about 20 to $25 \%$ would have natural healing and 25 to $30 \%$ would remain chronically ill, thus continuing to spread the disease in the community. ${ }^{1,2,4}$

According to the World Health Organization (WHO) report of 2007, one-third of the world's population is estimated to be infected with the causative organism, mycobacterium tuberculosis, hence at risk of developing the active disease. Africa accounts for almost a third of the global total, and has the highest incidence and prevalence rates in which 13 of the 15 countries with the highest incidence rates in the world, and 9 of the 22 High Burden Countries (HBCs). ${ }^{5}$

Ethiopia is among the world's top 22 TB HBCs, and the country had an estimated annual TB incidence rate of $300 / 100,000$, mortality rate of 54/100,000, and the prevalence of all forms TB was 480/100,000. ${ }^{6}$

About $40-70 \%$ of HIV patients in Ethiopia are co-infected with TB. The Ethiopia Federal Ministry of Health (MOH) hospital statistical data reveals that TB is the leading cause of morbidity, one of the three major causes for hospital admission, and the second killer next to malaria.?

The main objective of TB treatment is to cure the patient of TB; prevent death from active TB or its late effects; prevent relapse of TB; decrease transmission of TB to others and prevent the development of drug resistance TB. ${ }^{2,3,8,9}$

Incomplete treatment may result in prolonged excretion of bacteria which may resist the drug, causes disease and lead to increased morbidity/mortality and the spread of the disease. ${ }^{10}$

Treatment outcome results serve as a proxy of the quality of TB treatment provided by a health care system. Ideally, treatment outcome in all patients should be routinely monitored by the epidemiological surveillance system. This would make it possible to recognize and amend system failures before the incidence and proportion of resistant isolates rise. However, treatment outcome of tuberculosis patients has not been assessed yet in Gimbi Town Health facilities. Therefore, this study is aimed to assess treatment outcomes of tuberculosis at Gimbi Town Health facilities. Hence, assessments of the status of treatment outcomes and specific factors which may contribute to unsuccessful treatment outcomes are important in order to improve TB management program. 


\section{Method and materials}

Facility based descriptive cross-sectional study was conducted at Gimbi Town health facilities from March $10^{\text {th }}$ to $25^{\text {th }}, 2014$. Oromia region, West Ethiopia. A total of 162 TB patients' medical records on the treatment during the last one year (between July $1^{\text {st }} 2013$ E.C to June 302014 was included in the study. In this study treatment refers to defaulter, treatment complete, treatment failure, cured, died after initiation of TB treatment. Defaulter regarded as a patient who has been on treatment for at least four weeks and whose treatment interrupted for more than eight consecutive weeks or cumulative period of more than 12 weeks. Treatment completed is those patients who completed their course of anti TB drugs. Treatment failure (F) refers to a patient who remains or becomes again smear positive 5 months or later during treatment. We call Cured when a patient whose sputum smear or culture was positive at the beginning of the treatment but who was smear or culture negative in the last month of treatment and on at least one previous occasion. Died refers to a patient who died from any cause during the course of treatment.

Treatment success defined as cure (smears negative at treatment completion and on at least (one previous occasion) plus treatment completion without confirmation by smear microscopy cured or complete treatment poor Outcome includes defaulter, failure, died, and transfer out whereas. Good outcome includes cured and treatment completed.

Data extraction sheet was adopted from standard unit TB registration to collect basic information treatment outcome. Finally, the collected data were entered to master sheet and then analyzed. The result of the study was presented using table, figure and with narrative descriptions. Epi info version 3.5.4 was used to analyze the data. The association between variables was calculated using Chi-square test and $\mathrm{p}$-value of $<0.05$ was considered as significant.

Official letter was obtained from Jimma University Collage of Public Health and Medical Science, Department of Nursing and was given to Gimbi Town health facilities and then after obtaining permission, the data collection was commenced. All information that was obtained from the medical records was treated confidentially.

\section{Result}

\section{Socio-demographics characteristic}

A total of 162 TB patients were registered at Gimbi Town public health facilities from July $1^{\text {st }} 2004$ E.C to June 30, 2005 E.C among which $96(59.3 \%)$ were males and 66(40.7\%) were females with the mean age of 32.4years. Majority of the patient were in the age group $15-24(30.3 \%)$ and $120(74.1 \%)$ of live in Gimbi Town and the rest 42(25.9\%) were from neighbor districts Table 1.

Among 162 registered patients, 104(64.2\%) were PTB cases whereas 58(35.8\%) were EPTB. Regarding PTB cases, 71(68\%) were P.Neg and $33(32 \%)$ were P.Pos. In terms of TB patient categories, the majority of them $146(90.1 \%)$ were new, and the least $1(0.6 \%)$ were in defaulter patient category. It was noticed that $120(74.1 \%)$ were nonreactive and $38(23.5 \%)$ were reactive and the rests were unknown status on HIV test (Figures 1-3).

According to this study, the mean average weight at the beginning of intensive and continuation phases was $49.4 \mathrm{~kg}$ and $51.4 \mathrm{~kg}$ respectively. In addition for 43(26.5\%) of patients weight was not taken at the beginning of continuation phase Table 2. Regarding the smear conversion result of sputum smear positive TB patients, $27(81.8 \%)$ of them showed negative bacteriology result at the end of $2^{\text {nd }}$ month and $23(69.7 \%)$ and $22(66.7 \%)$ at $5^{\text {th }}$ and $6^{\text {th }}$ months respectively Table 3 .

Table I Socio demographic characteristics of TB Patients who completed treatment at Gimbi Town health facilities, Western Oromia, Ethiopia, from July Ist 2004 E.C to June 30, 2005 E.C

\begin{tabular}{lll}
\hline Socio-demographic variables & Frequency & Percent (\%) \\
\hline Age & & \\
Male & 96 & 59.3 \\
Female & 66 & 40.7 \\
Age & & \\
$<15$ & 9 & 5.5 \\
$15-24$ & 49 & 30.3 \\
$25-34$ & 46 & 28.4 \\
$35-44$ & 25 & 15.4 \\
$45-54$ & 16 & 9.9 \\
$>55$ & 17 & 10.5 \\
Residence & & \\
Urban & 120 & 74.1 \\
Rural & 42 & 25.9 \\
\hline
\end{tabular}

Type of TB
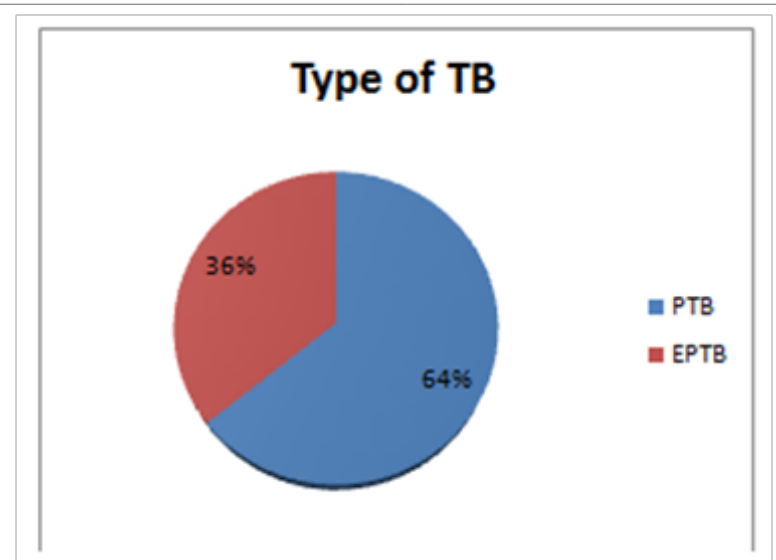

- EPTB

Figure I Type of tuberculosis among patients in Gimbi town health facilities from July Ist 2004 to June 30/2005 E.C.

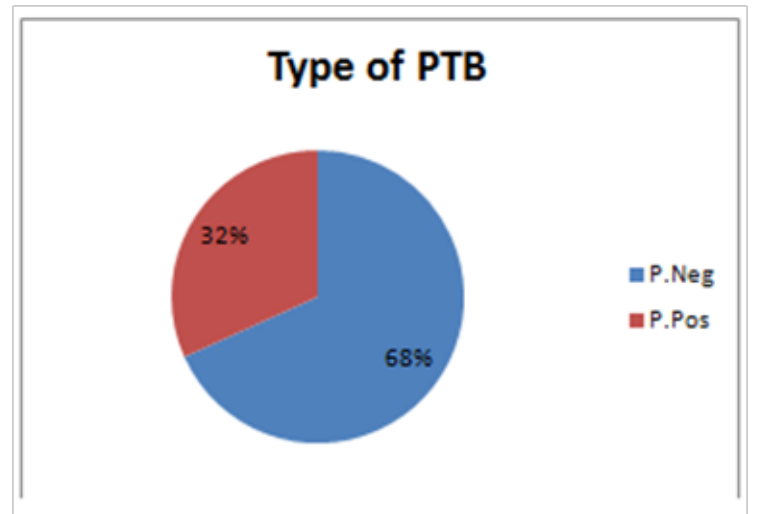

Figure 2 Type of PTB among patients in Gimbi town health facilities from July Ist 2004 to June 30/2005 E.C. 


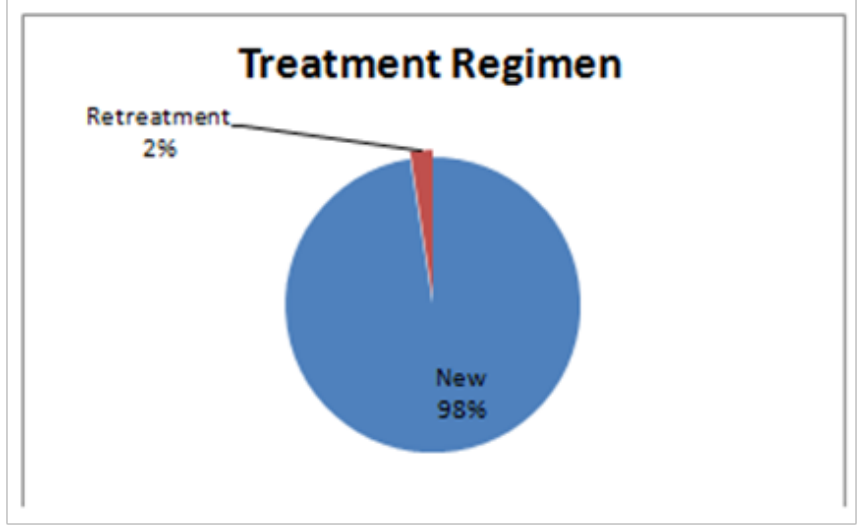

Figure 3 Treatment Regimen of tuberculosis among patients in Gimbi town health Facilities from July I ${ }^{\text {st }} 2004$ to June 30/2005 E.C.

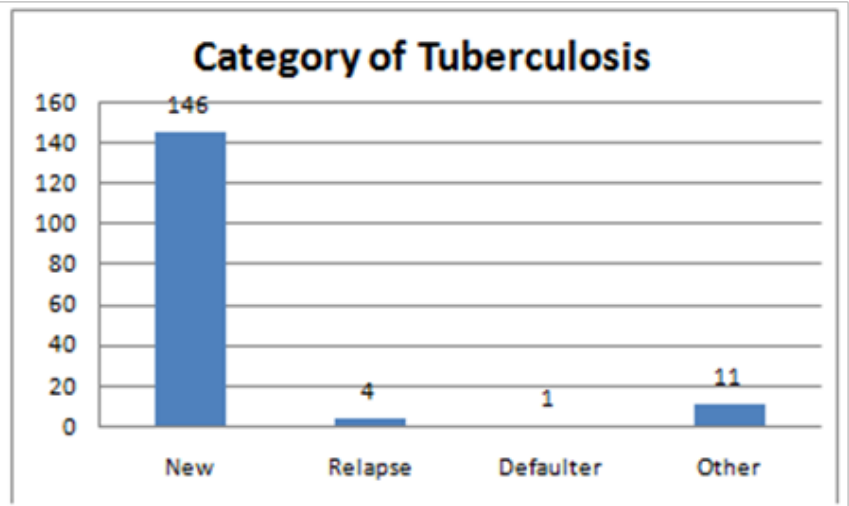

Graph I Category of tuberculosis among patients in Gimbi town health facilities from July I ${ }^{\text {st }} 2004$ to June 30/2005 E.C

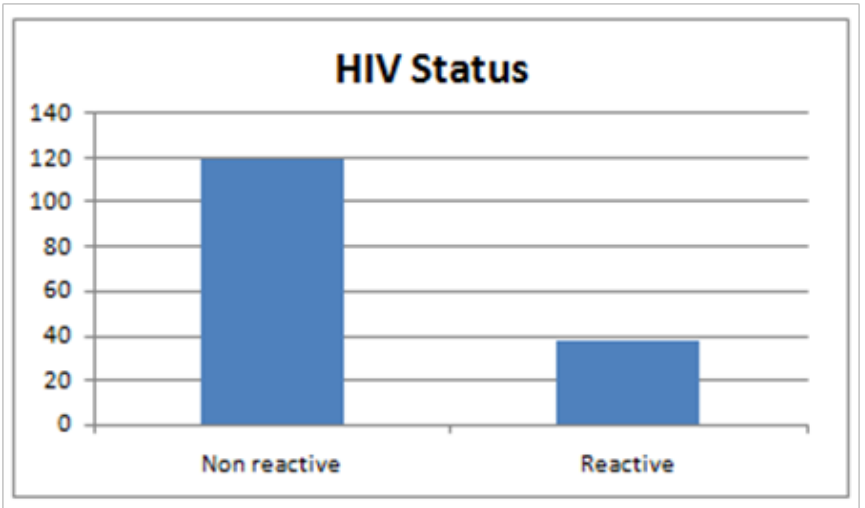

Graph 2 HIV test result of tuberculosis patients at Gimbi town health facilities from July Ist 2004 to June 30/2005 E.C.

Table 4 Frequency distribution of TB treatment outcomes at Gimbi Town health facilities, Western Oromia, Ethiopia from July Ist 2004 E.C to June $30 / 2005$ E.C

\begin{tabular}{|c|c|c|c|c|c|c|c|c|c|c|c|c|c|}
\hline \multirow[t]{3}{*}{ Variables } & \multirow[t]{3}{*}{ Category } & & \multirow[t]{3}{*}{$\begin{array}{l}\text { Total } \\
\text { registered }\end{array}$} & \multicolumn{7}{|c|}{ Treatment outcome } & & & \\
\hline & & & & \multicolumn{2}{|c|}{ Cured } & \multicolumn{2}{|c|}{ Completed } & \multicolumn{2}{|c|}{ Defaulted } & \multirow{2}{*}{$\begin{array}{l}\text { Died } \\
\text { Freq. }\end{array}$} & \multicolumn{2}{|c|}{ Transfer Out } & \multirow[b]{2}{*}{$\%$} \\
\hline & & & & Freq. & $\%$ & Freq. & $\%$ & Freq. & $\%$ & & $\%$ & Freq. & \\
\hline \multirow{4}{*}{ Types of TB } & \multirow{2}{*}{ PTB } & P.Pos & 33 & 22 & 66.77 & I & 3 & 3 & 9.1 & 1 & 3 & 6 & 18.2 \\
\hline & & P.Neg & 71 & & & 53 & 74.4 & 2 & 2.8 & 2 & 2.8 & 14 & 19.7 \\
\hline & EPTB & & 58 & & & 44 & 75.8 & 0 & 0 & 3 & 5.2 & 11 & 19 \\
\hline & Total & & 162 & 22 & 13.6 & 98 & 60.5 & 5 & 3.1 & 6 & 3.7 & 31 & 19.1 \\
\hline
\end{tabular}

Table 2 Weight based frequency distribution of treatment outcomes of TB patients at Gimbi town health facilities, Western Oromia, Ethiopia from July $\left.\right|^{\text {st }}$ 2004 E.C to June 30/2005 E.C

\begin{tabular}{lll}
\hline Weight of TB patients & Frequency & Percent (\%) \\
\hline Initial Weight & & \\
$8-14$ & 1 & 6 \\
$21-29$ & 3 & 1.9 \\
$30-39$ & 19 & 11.7 \\
$40-54$ & 90 & 55.6 \\
$55-75$ & 47 & 29 \\
\hline
\end{tabular}

Weight at the beginning of continuation phase

$\begin{array}{lll}8-14 & 1 & 0.6 \\ 21-29 & 1 & 0.6 \\ 30-39 & 6 & 3.7 \\ 40-54 & 68 & 42.0 \\ 55-75 & 43 & 26.5\end{array}$

Table 3 Smear Conversion based frequency distribution of treatment outcome of Tb patients at Gimbi town health facilities, western Oromia, Ethiopia from July Ist 2004 E.C to June 30/2005 E.C

\begin{tabular}{lll}
\hline Sputum follows up & Frequency & Percent (\%) \\
\hline At 2nd or 3rd months & & \\
Positive & 2 & 6.1 \\
Negative & 27 & 81.8
\end{tabular}

At 5th month

$\begin{array}{lll}\text { Positive } & 0 & 0 \\ \text { Negative } & 23 & 100\end{array}$

At 6th or 8th months

$\begin{array}{lll}\text { Positive } & 0 & 0 \\ \text { Negative } & 22 & 100\end{array}$

Among 162 patients who were on treatment for TB between the study period, $98(60.5 \%)$ were completed their course of treatment while $22(13.6 \%)$ of smear positive PTB patient were declared cured at the end of the treatment $5(3.1 \%)$ defaulted their treatment, $6(3.7 \%)$ of them died before completing their treatment. The cure rate was $66.7 \%$ and that of treatment success rate (Cured plus treatment completed) was $69.7 \%$. Out of all medical records of TB patients studied, 31(19.1\%) were transferred out and no available record of treatment outcome Table 4. 
Table Continued...

\begin{tabular}{|c|c|c|c|c|c|c|c|c|c|c|c|c|}
\hline \multirow[t]{3}{*}{ Variables } & \multirow[t]{3}{*}{ Category } & \multirow[t]{3}{*}{$\begin{array}{l}\text { Total } \\
\text { registered }\end{array}$} & \multicolumn{7}{|c|}{ Treatment outcome } & & & \multirow[b]{3}{*}{$\%$} \\
\hline & & & \multicolumn{2}{|l|}{ Cured } & \multicolumn{2}{|c|}{ Completed } & \multicolumn{2}{|c|}{ Defaulted } & \multirow{2}{*}{$\begin{array}{l}\text { Died } \\
\text { Freq. }\end{array}$} & \multicolumn{2}{|c|}{ Transfer Out } & \\
\hline & & & Freq. & $\%$ & Freq. & $\%$ & Freq. & $\%$ & & $\%$ & Freq. & \\
\hline \multirow{5}{*}{$\begin{array}{l}\text { Category of } \\
\text { TB }\end{array}$} & New & 146 & 20 & 13.7 & 90 & 61.6 & 5 & 3.4 & 4 & 2.7 & 27 & 18.5 \\
\hline & Relapse & 4 & 2 & 50 & 0 & 0 & 0 & 0 & 0 & 0 & 2 & 50 \\
\hline & $\begin{array}{l}\text { Return after } \\
\text { Default }\end{array}$ & I & 0 & 0 & 0 & 0 & 0 & 0 & 0 & 0 & I & 100 \\
\hline & Others & 11 & 0 & 0 & 8 & 72.7 & 0 & 0 & 2 & 18.2 & I & 9.1 \\
\hline & Total & 162 & 22 & 13.6 & 98 & 60.5 & 5 & 3.1 & 6 & 3.7 & 31 & 19.1 \\
\hline
\end{tabular}

According to this study, the HIV status, treatment regimen and classification) have no statistically significant association with TB place of residence have significant impact on TB treatment out treatment outcome Table 5. come with p-value $(\mathrm{P}<0.05)$. The other factors (Gender and TB

Table 5 Factors affecting treatment outcome of TB at Gimbi Town health facilities, Western Oromia, Ethiopia from July Ist 2004 E.C to June $30 / 2005$ E.C

\begin{tabular}{|c|c|c|c|c|}
\hline \multirow[t]{2}{*}{ Factors } & \multirow[t]{2}{*}{ Factors classification } & \multicolumn{2}{|c|}{ Outcome } & \multirow[t]{2}{*}{$\mathbf{X}^{2} / \mathbf{P}$ aValue } \\
\hline & & Poor & Good & \\
\hline \multirow{2}{*}{ HIVIAIDS status } & Positive & 8 & 26 & \multirow{2}{*}{$X^{2} \mathrm{Cal}=16.07,(d f=I) p=0.000$} \\
\hline & Negative & 2 & 93 & \\
\hline \multirow{2}{*}{ Gender } & Male & 6 & 70 & \multirow{2}{*}{$X^{2} \mathrm{Cal}=0.059,(d f=I) p=0.807$} \\
\hline & Female & 5 & 50 & \\
\hline \multirow[b]{2}{*}{ TB classification } & Pulmonary & 8 & 77 & \multirow{2}{*}{$X^{2} \mathrm{Cal}=0.36,(d f=I) p=0.54$} \\
\hline & Extra pulmonary & 3 & 44 & \\
\hline \multirow{2}{*}{ Pulmonary TB } & Pulmonary pose & 5 & 22 & \multirow{2}{*}{$X^{2} \mathrm{Cal}=2.5,(\mathrm{df}=\mathrm{I}) \mathrm{p}=0.1 \mathrm{I}$} \\
\hline & Pulmonary negative & 4 & 53 & \\
\hline \multirow{2}{*}{ Treatment Regimen } & New & 11 & $14 \mid$ & \multirow{2}{*}{$X^{2} \mathrm{Cal}=9.3,(\mathrm{df}=\mathrm{I}) \mathrm{p}=0.002$} \\
\hline & Retreatment & 2 & 2 & \\
\hline \multirow{2}{*}{ Place of residence } & Rural & 0 & 35 & \multirow{2}{*}{$X^{2} \mathrm{Cal}=4.37,(\mathrm{df}=\mathrm{l}) \mathrm{p}=0.03$} \\
\hline & Urban & 11 & 85 & \\
\hline
\end{tabular}

\section{Discussion}

In this facility based descriptive cross-sectional study, information on the treatment outcome of medical records of all types of TB patients across the year during the study period were assessed in Gimbi Town Health Facilities, Western Oromia, Ethiopia. This study revealed that a total of $120(74 \%)$ patients have satisfactory treatment outcome and the rest $42(26 \%)$ were with bad outcome (defaulter, Died, treatment failure and transfer out). Among the smear positive pulmonary tuberculosis registered, 22 of them were declared cured with cure rate of $66.7 \%$ and one case was treatment completed with a total of $69.7 \%$ treatment success rate. This result was almost similar when compared to a study conducted in France in 2009 which shows $70 \%$ cure rate and $72.8 \%$ treatment success rate. In addition a study done in Cameroon Baptist convention health board tuberculosis treatment centers in 2011 also showed similar treatment out come with the above findings. In contrarily, when compared to a WHO target of $85 \%$ TSR and $90 \%$ of CR the results were very low. The difference might be due to poor adherence of patient with treatment, poor implementation of DOTs strategy and some co-morbid diseases such as HIV/AIDS.
In cases of patients on retreatment regimen the cure rate and TSR were $50 \%$ which is very low when compared to the TSR (83\%) observed among the $22 \mathrm{HBCs}$ and $85 \%$ TSR suggested by WHO. This under achievement may be due to poor adherence of health professionals with treatment guideline, poor implementation of DOTs strategy. This study also demonstrated that the death rate all forms of tuberculosis patients was $3.7 \%$ which is similar with the study conducted at Gondar University Teaching Hospital that is (3.4\%).

On the other hand, the default rate in this study was (3.1\%) which is relatively lower than the average $6.2 \%$ among the $22 \mathrm{HBCs}$ In addition, this study showed that $9.1 \%$ of defaulters followed by $2.8 \%$ were from potentially infectious smear positive and smears negative PTB patients respectively which might be as the result of poor adherence to Directly Observed Treatment of short course (DOTs), defaulter tracing mechanism.

The result of the study also indicated that HIV/AIDs has statistically significant impact on TB treatment outcome and patients with new treatment regimens have more good outcome than those 
patients with retreatment regimen In case of place of residence, a patient from rural area are with good treatment outcome than those from urban area $(\mathrm{P}<0.05)$.

\section{Conclusion}

This study has attempted to come up with the conclusion that there are multiple factors associated with bad treatment outcome. HIV positive status, previously treated cases and residence are significantly associated with bad treatment outcome.

\section{Acknowledgements}

None.

\section{Conflict of interest}

The authors declare no conflict of interest.

\section{References}

1. Guidelines for clinical and programmatic management of TB, TB/HIV and leprosy in ethiopia 5th ed. Federal Ministry of Health. Ethiopia: Springer; 2013.
2. Standard treatment guideline for primary hospitals by drug administration and control authority of ethiopia; (2010).

3. CN Obion. Primary Health Care for Developing Countries. 2nd ed. Ethiopia: Evanseenio Printing and Publishing; 2007.

4. WHO Tuberculosis (TB). Global tuberculosis control; 2009.

5. World health organization (WHO). Global Tuberculosis Control. Geneva, Switzerland: Springer; 2009

6. World Health Organization (WHO). Global Tuberculosis Control. Geneva, Switzerland: Springer; 2010.

7. Federal democratic republic of ethiopia, Ministry of health (FMOH). TB/ HIV implementation guideline. Ethiopia: Springer; 2008.

8. Boa Q, Du Y, Lu c. Treatment outcome of new pulmonary tuberculosis in Guangzhou, China 1993-2002: a register-based cohort study. BMC. 2007;7:344.

9. World health organization. Treatment of tuberculosis. Geneva, Switzerland: Springer;

10. Grzybowski S, Enarson D. Results in pulmonary tuberculosis patients under various treatment program conditions. Bull Int Union Tuberc. 1978;53(2):70-75. 